\section{Resistance to extinction as a function of acquisition and extinction schedules and type of measurement}

ELMER H. DAVIDSON,' Oklahoma City University, Oklahoma City, Okla. 73106, and JAMES L. WALKER, Texas Technological College, Lubbock, Tex. 79406

Thirty albino rats were conditioned to bar-press for water under either continuous or 45-sec fixed-interval reinforcement schedules. Extinction was then carried out with either zero reinforcements, omission training, or noncontingent 45-sec fixed-interval reinforcements. Resistance to extinction was measured by the number of bar presses, the time, and the rate of responding to a no response for $15 \mathrm{~min}$ criterion It was concluded that the measure taken would affect many of the conclusions from extinction studies.

While the process involved in experimental extinction may be thought of as an active process, there is much controversy as to whether it is a process of inhibition of the response, learning an interfering response, or learning the discrimination that reinforcement is no longer contingent (Hall, 1966, pp. 276-291).

This study was designed to evaluate some of the theories of extinction as well as to show any differences in conclusions as a function of different measurements. Possible inconsistencies of the measures may account for some of the controversy in the area.

In order to predict from the inhibition theory of extinction, it was assumed that this inhibition must occur in the extinction stage of a factorial design rather than in the acqusition stage. So, while the level of learning in the acquisition stage was expected to produce some effects, the occurrence of reinforcements from differing schedules in the extinction stage was expected to produce more since the acquisition schedules were fairly similar. More reinforcements during extinction were expected to produce a greater resistance to extinction since habit strength should continue to increase. Therefore, from this theory, it was expected that a given extinction procedure would order groups, with the acquisition procedure simply ordering subgroups. For instance, as there were three extinction procedures, there was a predicted order of extinctions $(1-3)$. Then, when two acquisition 1-6). inhibition theory. difficult discrimination. procedures ( $a$ and $b$ ) were considered, the ranking became 1a, 1b, 2a, 2b, 3a, 3b (or

In order to predict from the interference theory, it was assumed that extinction is a function of learning a new response, and that this interfering response must be learned in the extinction stage, as in the case of the inhibition theory. The differences in predictions from these two theories would be produced because resistance to extinction would be expected to decrease as the probability of reinforcing competing responses increases in the interference theory but not the

In order to predict from the discrimination theory, it was assumed that extinction is a function of learning that reinforcement is no longer contingent upon the old responise and, therefore, the ease of the discrimination should be the determining factor. In this case, predictions were made simply by use of the ratio of reinforcements in acquisition to those in extinction. For instance, changing from continuous to zero reinforcements was considered an easy discrimination, while changing from a fixed-interval conditioning schedule to noncontingent reinforcements with the same interval was considered a

Two problems of rank ordering of groups were found. One was in deciding the relative effects of the different acquisition schedules (differences in the levels of learning), and the other was in deciding whether a conditioned or competing response was more likely to be reinforced in a given situation. The first was resolved by assuming small differences in the level of learning, and the second by assuming that the conditioned response was more likely unless appropriate controls

Table 1

Predicted and Observed Rank Orders of the Three Theories and Three Measures

\begin{tabular}{|c|c|c|c|c|c|c|}
\hline \multirow[b]{2}{*}{ Group } & \multicolumn{3}{|c|}{$\begin{array}{l}\text { Predicted Rank Order } \\
\text { for Each Theory }\end{array}$} & \multicolumn{3}{|c|}{$\begin{array}{c}\text { Observed Rank Order } \\
\text { of Each Measure }\end{array}$} \\
\hline & Inhibit & Interfer & Discrim. & Rs & Min & Rate \\
\hline$C-Z$ & 1 & 3 & 1 & $1(136)$ & $2 \quad(96)$ & $3(1.84)$ \\
\hline $\mathrm{C}-\mathrm{O}$ & 3 & 1 & 2 & $2(158)$ & $3(114)$ & $1(1.43)$ \\
\hline $\mathrm{C}-\mathrm{Nl} \mathrm{I}$ & 5 & 5 & 3 & $5(443)$ & $6(185)$ & $4(2.33)$ \\
\hline FI-Z & 2 & 4 & 4 & $4(184)$ & 1 (81) & $5(2.85)$ \\
\hline $\mathrm{FI}-\mathrm{O}$ & 4 & 2 & 5 & $3(179)$ & $4(116)$ & $2(1.83)$ \\
\hline II-NFI & 6 & 6 & 6 & $6(629)$ & $5(148)$ & $6(3.25)$ \\
\hline
\end{tabular}

The mean of each group is given in parenthesis beside the observed rank orders. Since the mean rates were calculated from individual rates, they sometimes are different from the score which would be derived from the mean number of $R S$ and mean number of min. 
given two sessions of 50 reinforcements each. One session was during the early morning and the other during the afternoon.

On Day 5, Ss were divided randomly (by use of random number tables) into two groups and given 10 continuous reinforcements; and then, one group was switched to FI for $\mathbf{4 0}$ reinforcements. The other was maintained on $\mathrm{C}$ for $\mathbf{4 0}$ more reinforcements. On Day 6, Ss were given 50 reinforcements; and on Day 7, Ss were given 60 reinforcements on the assigned schedule. According to Wyckoff (1950), behavior should have been (and seemed to be) asymptotic at that point.

On Day 8, each of the two groups were divided randomly (by use of tables) into three groups and assigned to $\mathrm{Z}, \mathrm{O}$, or NFI. They were given 10 reinforcements on the previously assigned acquisition schedule and then placed on the assigned extinction schedule. They were left in the apparatus until the criterion of no response for $15 \mathrm{~min}$ had been reached.

Spontaneous recovery (SR) was measured in one additional session. On Day 9 , Ss were returned to the apparatus on the same extinction schedule as before and left there until the same extinction criterion had been reached.

$$
\text { RESULTS }
$$

Each measure of extinction was subjected to an analysis of variance. Only the extinction schedule had an effect if either the number of responses $[F(2,24)=9.63, p<.01]$ or the number of minutes to extinction $[F(2,24)=7,198$, $p<.01]$ were used. Both the acquisition and extinction schedules produced effects $[F(1,24)=6.81, p<.05 ; F(2,24)=5.21$, $\mathrm{p}<.05]^{\text {'if the rate of responding }}$ (responses per minute minus the 15 criterion minutes) was used as the measure. It was seen that in no case was there an interaction.

Table 2

Rank-Order Correlations Between Predicted and Observed Rank Orders for Each Theory and Each Measure

\begin{tabular}{lccc}
\multicolumn{4}{c}{ Theory and Each Measure } \\
\hline & \multicolumn{3}{c}{ Measure of Extinction } \\
\cline { 2 - 4 } $\begin{array}{l}\text { Extinction } \\
\text { Theory }\end{array}$ & $\begin{array}{c}\text { Number } \\
\text { of Rs }\end{array}$ & $\begin{array}{l}\text { Number } \\
\text { of Min }\end{array}$ & $\begin{array}{c}\text { Rate } \\
(\mathrm{R} / \mathrm{m})\end{array}$ \\
\hline Inhibition & .85 & .89 & .37 \\
Interference & .89 & .43 & .94 \\
Discrimination & .77 & .37 & .54 \\
\hline
\end{tabular}

In Table 1, the predicted (a priori) rank orders are summarized with the observed rank orders and means for each group and measure. Table 2 gives the rank-order correlation of the theoretical predictions with the rank order of each observed measure. Inspection showed that if the number of responses to extinction was used, not much difference was found between theoretical predictions. However, with this measure, the correlation produced by the interference theory was slightly higher. If the measure used was minutes to extinction, then a larger difference was found. However, using minutes to extinction inhibition theory produced the higher correlation. When the rate of responding was used, interference theory again showed a higher correlation than the other two. It was noted that in neither measure did the discrimination hypothesis produce the highest correlation.

The data from SR sessions were subjected to the analysis of variance. The extinction schedules had an effect with all measures [number of $R s, F(2,24)=12.38$, $\mathrm{p}<.01$; minutes to extinction, $\mathrm{F}(2,24)=6.62, \quad \mathrm{p}<.01 ;$ rate, $F(2,24)=3.46, p<.05]$, but there were no acquisition or interaction effects.

\section{DISCUSSION}

Of the data reported, Table 2 seemed most interesting. It was demonstrated that if one of the extinction theories is selected to predict behavior, then care should be taken to select the "right" measure to reflect the bias of the $E$. If the number of responses to extinction was used, then about the only conclusion would be that

Table 3

Spontaneous Recovery Means for Each Group and Each Measure

\begin{tabular}{|c|c|c|c|}
\hline \multirow[b]{2}{*}{ Group } & \multicolumn{3}{|c|}{ Measure of Spontaneous Recovery } \\
\hline & $\begin{array}{c}\text { Number } \\
\text { of Rs }\end{array}$ & $\begin{array}{l}\text { Number } \\
\text { of } \mathrm{M} \text { in }\end{array}$ & $\begin{array}{c}\text { Rate } \\
(\mathrm{R} / \mathrm{m})\end{array}$ \\
\hline C-Z & 44 & 44 & 1.09 \\
\hline $\mathrm{C}-\mathrm{O}$ & .25 & 31 & .73 \\
\hline C-NFI & 219 & 116 & 1.80 \\
\hline FI-Z & 61 & 42 & 2.03 \\
\hline FI-O & 69 & 65 & 1.02 \\
\hline FI-NFI & 157 & 90 & 1.80 \\
\hline
\end{tabular}

Since the mean rates were calculated from individual rates, they sometimes differ from the score which would be derived from the mean number of $R s$ and mean number of min. the three theories were nearly equally effective. If the number of minutes to extinction was used, then most support was found for an inhibition process in extinction. If the rate of responding during extinction was used, then the conclusion would tend to be for an interference process.

It was of interest to note that little support was found for a discrimination process in extinction. An interaction in the analysis of variance tables would have supported this theory. No interactions were found, and the correlations between predicted and observed rank orders were not very high.

Omission training may be different from traditional ideas of extinction. It was noted that as long as the animal bar-pressed at least every $45 \mathrm{sec}$, omission training was exactly like the zero reinforcement schedule. However, when the animal was not bar-pressing, the omission schedule was the same as the noncontingent fixed-interval schedule. The one thing that the omission training insured was that an interfering response must have occurred when reinforcement was presented. If the interference theory was considered, it is seen (Table 1) that the rate measure during extinction is suppressed by omission training. Also, it was found that the rate of responding during the spontaneous recovery session was suppressed by omission training.

Since no interaction was found in factorial analyses and the omission training had the noted effects during extinction plus the better predictions in two of the three measures "of extinction, the interference theory of extinction is better supported by these data.

\section{REFERENCES}

CAMPBELL, S. L. Resistance to extinction as a function of number - of shock-termination reinforcements. Journal of Comparative \& Physiological Psychology, 1959, 52, 754-758. HALL, J. F. The prychology of learning. Philadelphia: Lippincott, 1966.

WYCKOFF, L. B. Resistance to extinction of a lever pressing response in white rats as a function of number : of reinforcements. Unpublished Master's thesis, Indiana University, 1950. (In Campbell, 1959). NOTE

1. The data for this study were collected while the senior author was on the faculty of Texas Technological College. 